\title{
Impact of Frontline Demonstration in Adoption of Chickpea Production Technology by the Farmers of Sehore District, Madhya Pradesh, India
}

\author{
Mr. Rahul Parmar*, Dr. Sandhya Choudhary**, Dr. Abhay Wankhede** \\ Dr. V.K. Swarnakar*** \\ *M.Sc. Students 2017, College of Agriculture, Indore \\ ** Associate Professor, College of Agriculture, Indore \\ ***Professor \& Head of Extension Education, College of Agriculture, Indore
}

\begin{abstract}
Front Line demonstrations (FLDs) is a unique approach to provide an direct interface between researcher and farmers as the scientists are directly involved in planning, execution and monitoring of the demonstrations for the technologies developed by them and get direct feedback from the farmers. In the response of transfer of technology the recommendation of modern (improved) chickpea production technology a great emphasis was being paid by both the scientist and extension workers to boost up the productivity of chickpea in the area. In the present study an attempt has been made to examine the impact of frontline demonstration of chickpea in district Sehore where agricultural scientist had been conducted this programme at farm level. In case level of knowledge, as observed in low and medium category chickpea growers, found higher in non FLD adopter than FLD adopter whereas level of adoption, as observed in partial and incomplete category chickpea growers, found higher in non FLD adopter than FLD adopter.
\end{abstract}

\section{Introduction}

Chickpea is commonly known as gram which is one of the important pulse crop of India. About $65 \%$ of global area with $68 \%$ of Global chickpea is contributed by India. It is important point to note that chickpea continues to be the largest consumed pulse in home as well as industrial purpose comprising of about 50 per cent of total pulse production in India. Madhya Pradesh is one of the major chickpea producing states in India. The area of chickpea crop was 3482.24 thousand hectares with the production and productivity of 3820 thousand tonnes and $1096 \mathrm{~kg} / \mathrm{ha}$, respectively in the year 2013. (Source-Agri. Statistic at Glance 2014).

The Front Line Demonstration is to demonstrate newly released crop production and protection technologies and its management's practices in the farmer's field under different agro-climatic regions and farming situations with the objective to study the constraints of production factors contributing for higher production. Front line Demonstrations on chickpea were conducted on different aspects during 2000-01 to 2009. The yield gap between conventional practices and improved package of practices was much higher ranging from $21 \mathrm{~kg} / \mathrm{ha}$ to $349 \mathrm{~kg} / \mathrm{ha}$. There is urgent need to make stronger extension services for educating the cultivators in the implementation of improved technology. Under varietals demonstration, the technology gap was much higher i.e. $349 \mathrm{~kg} / \mathrm{ha}$ followed by management of fertilizer in chickpea $(191 \mathrm{~kg} / \mathrm{ha}$.). Growth and instability in chickpea yield, extent of adoption, on farm benefits, factors influencing adoption of improved cultivars and farmers perception of varietals traits and constraints are critically evaluated. The survey revealed that improved chickpea varieties showed distinctly superior performance over local cultivars in terms of yield, net income and per unit cost reduction, improving their cost and profit maximizing characteristics. There for the present investigation was under taken with the following objective.

1. To compare the performances of FLD and non FLD chickpea farmers

\section{Review of Literature}

Singh et al. (2004) studied the impact of front line demonstration in oilseed and impact study indicate that due to adoption of recommended scientific package, yields in oilseed crops under FLD were higher and superior in demonstration plots compared to local ones (farmers practice). Kirar et al. (2006) reported that frontline demonstration programme was effective in changing attitude, skill and knowledge of improved practices of HYV of urd including adoption this also improved the relationship between farmers and scientist and built confidence between them. The farmers who adopted demonstration acted also as source of information and pure seed for wider dissemination of HYV of urd for the farmers. Kangali (2012) revealed that in case of level of adoption, as observed in low category, 25.00 per cent farmers decreased in adopter condition over non adopter condition. On the other hand, in partial and full adoption condition 17.50 and 7.50 per cent farmers increased in adopter condition over non adopter condition respectively. Verma (2013) shows the distribution of 
beneficiaries according to their change of area after conducting the FLD on their field. The data reveals that of the total, 76 per cent were having low (up to $0.4 \mathrm{ha}$ ) area change, 16 per cent medium $(0.41-0.6 \mathrm{ha})$ and 8 per cent high (0.61 - 0.8 ha) area change of pulses the new production technologies through FLD. Teggelli et al. (2015) reported that The FLD produces a significant positive result and provided the researcher an opportunity to demonstrate the productivity potential and profitability of the latest technology, The productivity gain under FLD over existing practices of pigeon pea cultivation created greater knowledge, awareness and motivated the other farmers to adopt suitable production technology of pigeon pea in the district.

\section{Material \& Methods}

The sample of the study has been selected through multi-stage sampling technique. The study has been conducted in Sehore District of Madhya Pradesh. In Sehore district, Sehore block was selected purposively for the study because it has large area under chickpea cultivation and of the convenience to the researcher. A comprehensive list of chickpea growers adopted frontline demonstration in selected block was prepared with the help of "Scientist of chickpea project in College of Agriculture Sehore". From this list (60) respondents were selected randomly. To compare the impact of frontline demonstration, 60 chickpea growers was also be selected from the same village, who are not adopted the demonstration on their farm. For this purpose a list of chickpea growers were prepared who are not selected for frontline demonstration and from this list 60 farmers were selected randomly. Thus, total 120 farmers were respondents of present study.

\section{Knowledge about chickpea production technology:}

The knowledge regarding chickpea production technology refers to the idea hold regarding recommended and improved package of practices by the chickpea growers. It consisted of 9 practices followed by chickpea growers. The responses of the chickpea growers were obtained on 3 point continuum i.e. low, medium and high knowledge about chickpea production technology. The scoring was done in the order of 1,2 and 3 respectively

\section{Adoption level of chickpea production technology among the farmers:}

The extent of adoption of chickpea production technology of chickpea refers to the extent of adoption of recommended and chickpea production techniques and practices by chickpea growers on their farm. To measure the level of adoption, index of adoption developed by Shiyani (2001) was adopted. This scale consisted of 14 practices the whole chickpea production package of practices. The level of adoption was considered adopted and non adopted. The weightage of 3 for complete adoption, 2 for incomplete adoption and 1 for partial adoption of each practice was assigned. The total score obtained by the chickpea growers from all 14 practices was the adoption score of individual chickpea grower.

\section{Knowledge about chickpea production technology}

\section{Result \& Discussion}

Knowledge is a body of understood information possessed by an individual chickpea grower. Knowledge is defined as the things known to an individual and represented cognitive domain. The detail distribution of FLD and non FLD chickpea farmers as per their knowledge about chickpea production technology group has been presented in given Table -

Table:- Distribution of the respondents according to their knowledge about chickpea production technology.

\begin{tabular}{|c|c|c|c|c|c|}
\hline \multirow{2}{*}{ Characteristics } & \multirow{2}{*}{ Categories } & \multicolumn{4}{|c|}{ No. of respondents } \\
\cline { 3 - 6 } & & Adopter & $\%$ & Non Adopter & $\%$ \\
\hline \multirow{3}{*}{ Knowledge about chickpea production technology } & Low & 19 & $\mathbf{3 1 . 6 6}$ & $\mathbf{2 3}$ & $\mathbf{3 8 . 3 3}$ \\
\cline { 2 - 6 } & Medium & $\mathbf{2 2}$ & $\mathbf{3 6 . 6 8}$ & $\mathbf{2 3}$ & $\mathbf{3 8 . 3 3}$ \\
\cline { 2 - 6 } & High & 19 & $\mathbf{3 1 . 6 6}$ & $\mathbf{1 4}$ & $\mathbf{2 3 . 3 4}$ \\
\cline { 2 - 6 } & Total & $\mathbf{6 0}$ & $\mathbf{1 0 0}$ & $\mathbf{6 0}$ & $\mathbf{1 0 0}$ \\
\hline
\end{tabular}

Table showed that in case of adopter of frontline demonstration of chickpea growers, the majority (36.68\%) respondents perceived medium knowledge about chickpea production technology followed by high and low category of knowledge (31.66\%) respectively. Thus, it can be concluded that in case of adopter of frontline demonstration of chickpea growers, majority of the respondents perceived medium category regarding knowledge about chickpea production technology followed by high and low knowledge about chickpea production technology. In case of non adopter of frontline demonstration of chickpea growers the majority of (38.33\%) respondents perceived medium and low knowledge about chickpea production technology followed by high knowledge (23.34\%) respectively. Thus, it can be concluded that in case of non adopter of frontline demonstration of chickpea growers majority of the respondents perceived low and medium category knowledge about chickpea production technology followed by high knowledge about chickpea production technology. 


\section{Comparative adoption level among FLD and non FLD chickpea growers}

It is pertinent to have an idea regarding adoption score by FLD and non FLD chickpea growers for assessment the improvement in adoption of FLD adopters of chickpea production technology over non FLD adopters. The distribution of FLD and non FLD chickpea growers according to adoption score of chickpea production technology has been presented in Table bellow-

Table:-Distribution of FLD and non FLD chickpea growers according to adoption score of chickpea production technology.

\begin{tabular}{|c|c|c|c|c|}
\hline \multirow[b]{2}{*}{ S.No. } & \multirow[b]{2}{*}{ Recommended production technology } & \multicolumn{3}{|c|}{ Total adoption score perceived by } \\
\hline & & FLD adopter & $\begin{array}{c}\text { FLD non } \\
\text { adopter }\end{array}$ & $\begin{array}{l}\text { Change in FLD } \\
\text { over non FLD }\end{array}$ \\
\hline 1. & Method of field preparation & 144 & 127 & 17 \\
\hline 2. & Improved chickpea variety(JG-11\& JG-16) & 131 & 110 & 21 \\
\hline 3. & Seed rate $(75-80 \mathrm{~kg} / \mathrm{hectare})$ & 139 & 115 & 24 \\
\hline 4. & Seed treatment (Carbendazim at $1.5 \mathrm{~g} / \mathrm{kg}$ seed) & 132 & 124 & 8 \\
\hline 5. & $\begin{array}{l}\text { Method of sowing }(B y \text { Seed-Drill } \& \text { acc. to the } \\
\text { availability of machinery) }\end{array}$ & 133 & 116 & 17 \\
\hline 6. & Spacing $(30 \times 10 \mathrm{~cm})$ & 127 & 114 & 13 \\
\hline 7. & $\begin{array}{l}\text { FYM/Bio fertilizer application (5 to } 10 \text { Tonne/hact. \& } \\
\text { Rhizobium culture } 2-2.5 \mathrm{~g} / \mathrm{kg} \text { seed) }\end{array}$ & 124 & 110 & 14 \\
\hline 8. & Fertilizers (NPK) (50:150:70kg/hact) & 117 & 105 & 12 \\
\hline 9. & Intercultural operations & 136 & 108 & 28 \\
\hline 10. & Irrigation (2 Pre-flowering \& Pod formation) & 137 & 112 & 25 \\
\hline 11. & Plant Protection Measures & 128 & 110 & 18 \\
\hline 12. & Proper method of harvesting and threshing & 135 & 113 & 22 \\
\hline 13. & Applying Post harvest technology & 137 & 115 & 22 \\
\hline 14. & Method of marketing & 138 & 112 & 26 \\
\hline 15. & Average of overall technology adoption & 133 & 114 & 19 \\
\hline \multirow[t]{2}{*}{16.} & t. value, calculated & \multicolumn{3}{|c|}{4.10} \\
\hline & Table t'value & \multicolumn{3}{|c|}{2.99} \\
\hline
\end{tabular}

* Significant at $5 \%$ level of significance with 13 d.f.

14 components of chickpea production technology under frontline demonstration were considered to examine the adoption level by FLD adopter and FLD non adopter chickpea growers. In present segment of study, the detail of these 14 components of technology along with overall level of adoption were compared to find out difference in the adoption level among FLD adopter and FLD non adopter chickpea growers. The total score values of the "average of overall technology adoption" perceived by adopter FLD chickpea growers were found to 133. On the other hand, the total score values of the "average of overall technology adoption" perceived by non adopter FLD chickpea growers were found to 114. These two values of adoption score determine the change in score by FLD chickpea grower level of adoption over non FLD chickpea growers and i.e. found to be 19 score. Which, shows the positive effect by gaining 19 average score in level of adoption of overall chickpea production technology by FLD chickpea growers over non FLD chickpea growers. The calculated ' $t$ ' value 4.10 at 5 per cent level with 13 d.f. was higher than the Table value of ' $t$ ' 2.99 . This was declared to be significant. Therefore, it may be concluded that the data provides enough evidence of higher level of adoption of chickpea production technology by FLD chickpea growers over non FLD chickpea growers. This clearly shows that as regard the level of adoption of chickpea production technology there was a significant difference between FLD adopter and non FLD adopter.

\section{Comparison in the performances of FLD and non FLD chickpea farmers}

The improvement or change in level of knowledge and level of adoption of FLD adopter chickpea growers over FLD non adopter chickpea growers due to adoption of frontline demonstration of chickpea production practices at field level determine the performance of the FLD. The frontline demonstration is a extension practices on the basis of seeing and believing in which the improved knowledge and adoption level of farmers ultimately effected in higher production, productivity, income, employment and simultaneously increased in socio-economic status of farmers. The possible impact of chickpea production technology on knowledge and adoption of chickpea growers is not yet evident. Following Table 4.17 clearly indicated the exiting knowledge and adoption status of adopter and non-adopter of frontline demonstration of chickpea growers in same situation of study area. 
Table-: Impact of frontline demonstration on improved chickpea production technology on knowledge and adoption of chickpea growers.

\begin{tabular}{|c|c|c|c|c|}
\hline S.No. & Category & Adopter Percentage & Non- adopter Percentage & Additional over non-adopter Percentage \\
\hline A. & \multicolumn{3}{|c|}{ Extent of Knowledge } \\
\hline 1 & Low & $\mathbf{3 1 . 6 6}$ & $\mathbf{3 8 . 3 3}$ & $\mathbf{- 6 . 6 7}$ \\
\hline 2 & Medium & $\mathbf{3 6 . 6 8}$ & $\mathbf{3 8 . 3 3}$ & $\mathbf{- 1 . 6 5}$ \\
\hline 3 & High & $\mathbf{3 1 . 6 6}$ & $\mathbf{2 3 . 3 4}$ & $\mathbf{+ 8 . 3 2}$ \\
\hline B. & \multicolumn{3}{|c|}{ Extent of Adoption } \\
\hline 1 & Partial & $\mathbf{2 3 . 3 4}$ & $\mathbf{3 1 . 6 7}$ & $\mathbf{- 8 . 3 3}$ \\
\hline 2 & Incomplete & $\mathbf{3 1 . 6 6}$ & $\mathbf{4 6 . 6 6}$ & $\mathbf{- 1 5 . 0 0}$ \\
\hline 3 & Complete & $\mathbf{4 5 . 0 0}$ & $\mathbf{2 1 . 6 7}$ & $\mathbf{2 3 . 3 3}$ \\
\hline
\end{tabular}

It is apparent from the data that there is clear cut shifting in number of (percentage) chickpea growers as they perceived level of knowledge and adoption due to front line demonstration from low category to higher one. In case level of knowledge, as observed in low and medium category chickpea growers, found higher in non FLD adopter than FLD adopter by 6.67 per cent and 1.65 per cent respectively. On the other hand, in high knowledge category chickpea growers, found higher in FLD adopter than non FLD adopter by 8.32 per cent.

Hence, it is concluded that the number of low and medium knowledge level of chickpea growers found to decrease in adopter condition over non adopter condition respectively. On the other hand, in high knowledge condition the chickpea growers found to increase in adopter condition over non adopter condition. In case level of adoption, as observed in partial and incomplete category chickpea growers, found higher in non FLD adopter than FLD adopter by 8.33 per cent and 15.00 per cent respectively. On the other hand, in complete adoption category chickpea growers, found higher in FLD adopter than non FLD adopter by 23.33 per cent.

Hence, it is concluded that the number of partial and incomplete level of adoption chickpea growers found to decrease in adopter condition over non adopter condition respectively. On the other hand, in complete adoption condition the chickpea growers found to increase in adopter condition over non adopter condition.

\section{Level of adoption of FLD and non FLD chickpea growers}

Study concluded that in case of adopter farmers, majority of the respondent were in complete level of adoption followed by incomplete and partial category respectively regarding adoption of chickpea production technology. The main aim of frontline demonstration is to demonstrate newly released crop production and protection technologies and its management practices in the farmers' field. The technologies are demonstrated for the first time by the scientists themselves before being fed into the main extension system. That is reason the farmers are fully convinced regarding technology demonstrated on their farm and they followed incomplete adoption of chickpea production technology at their farm. This finding is in conformity with the findings as reported by Singh (2001) and Patel et al. (2003).

\section{Compare the performance of FLD and non FLD chickpea production technology}

It is concluded that the number of low and medium knowledge level of chickpea growers found to decrease in adopter condition over non adopter condition respectively. On the other hand, in high knowledge condition the chickpea growers found to increase in adopter condition over non adopter condition. Frontline Demonstration is a form of applied research through agricultural scientists or agricultural extension personnel in which package of practices of crop on selected farmers' fields with a view to demonstrate the potentiality of the technologies to participating farmers. This is on the basis of seeing and believing that why the low and medium knowledge farmers are shifting towards high knowledge. This finding is in conformity with the findings as reported by Singh et al. (2005), Teggelli et al. (2015).

It is concluded that the number of partial and incomplete level of adoption chickpea growers found to decrease in adopter condition over non adopter condition respectively. On the other hand, in complete adoption condition the chickpea growers found to increase in adopter condition over non adopter condition. Front Line demonstrations (FLDs) is a unique approach to provide an direct interface between researcher and farmers as the scientists are directly involved in planning, execution and monitoring of the demonstrations for the technologies developed by them. That is the reason the demonstrated practices become high profitable and high remunerative, which attract low and medium package of practices adopter towards high adoption. This finding is in conformity with the findings as reported by Narayanaswamy and Eshwarapa (1998), Kirar et al. (2004), Sing (2009), Kangali (2012) and Verma (2013). 


\section{Reference}

[1] Kirar, B.S.; Mahajan, S.K. and Nashine, R. (2004). Impact of technology practices on the productivity of soybean in FLD. Ind. Res. J. Ext. Edu. 5(1):15-17.

[2] Kangali, Sarita (2012). A study on impact of frontline demonstration of chickpea in Sehore district of Madhya Pradesh. M.Sc. (Ag.) Thesis Submitted to the Rajmata Vijayaraje Scindia Krishi Vishwa Vidyalaya, Gwalior.

[3] Narayanswamy,C. and Eshwarapa,G. (1998). Impact of Front Line Demonstration. Indian Journal of Extension Education. 34(1\&2):14-15.

[4] Shiyani, R.L. (2001). “Adoption of Improved Chickpea Varieties: Evidences from Tribal Region of Gujarat”. Indian Journal of Agricultural Extension, Vol. 55, (2), pp. 159-171.

[5] Teggelli, Raju G.; Patil, D.H.; Ananda; Naik; Zaheer Ahamed, B. and Patil, M.C. (2015). Impact of Frontline Demonstration on the yield and economics of pigeonpea in Kalaburgi district of Karnataka State. I.J.S.N. 6(2):224-227.

[6] Verma, Deependra Prakash (2013). A study on impact of Front Line Demonstrations on pulses by Krishi Vigyan Kendra, Panna M.P. M.Sc. (Ag.) Thesis Submitted to Jawaharlal Nehru Krishi Vishwa Vidyalaya, Jabalpur. 